\title{
Influence of mating and vaginocervical stimulation on rat uterine activity*
}

\author{
J. P. Toner† and N. T. Adler
}

Psychology Department, University of Pennsylvania, 3815 Walnut Street T3, Philadelphia, PA

19104, U.S.A.

\begin{abstract}
Summary. Twenty female rats were implanted with myometrial electrodes and intrauterine balloons to study the effects of mating on uterine contractile activity. Mating produced both immediate and delayed effects. Uterine activity typically doubled during the period of active mating (the immediate effect), then briefly returned to the premating activity level after ejaculation. Beginning $5 \mathrm{~min}$ after the ejaculation, the delayed effect of mating was observed: contractile activity increased when the baseline activity had been low, but decreased when baseline was fast. This delayed effect lasted for $30 \mathrm{~min}$ to several hours. Vaginocervical stimulation seemed to play a critical role in these responses: artificial vaginocervical stimulation mimicked the response while vigorous mounting by males that were prevented from intromitting did not evoke these responses. Vaginocervical stimulation, whether mating-derived or experimenterdelivered, produced immediate and delayed effects on uterine contraction rate.
\end{abstract}

\section{Introduction}

Despite the importance of sperm transport to the issues of fertility and infertility, our understanding of this process is incomplete (Kelly, 1962; Fox \& Fox, 1967; Moghissi, 1969; Hafez, 1973; Settlage, Motoshima \& Tredway, 1973; Viring, Einarsson, Jones \& Larsson, 1980; Overstreet \& Tom, 1982; Hawk, 1983).

In the rat, spermatozoa must first pass through a tightly constricted cervix (Genell, 1939). This process requires an adequate number of pre-ejaculatory intromissions (Adler, 1969), a well-placed copulatory plug (Matthews \& Adler, 1977), and is facilitated by the pair of rats remaining stationary for at least $1 \mathrm{sec}$ during the ejaculation response (Matthews \& Adler, 1978, 1979; Toner, Attas \& Adler, 1986). Transcervical sperm transport is, however, only the first stage of sperm migration. Once past the cervix, spermatozoa must traverse $4 \mathrm{~cm}$ of fluid-filled uterus to reach the oviducts.

Transuterine sperm transport may depend on adequate and appropriate uterine contractions. Three lines of evidence suggest that spermatozoa are actively transported through the uterus by muscular contractions: (a) spermatozoa arrive at the oviducts too quickly (Hartman \& Ball, 1931; VanDemark \& Moeller, 1951; Settlage et al., 1973) for their intrinsic motility to have brought them there (Harvey, 1960); (b) inert materials placed in the caudal uterus are quickly transported to the oviducts (Amerbach, 1930; Krehbiel \& Carstens, 1939; Egli \& Newton, 1961); and (c) direct observation has revealed that uterine contractions move spermatozoa (or dye) up and down the uterine horns of rats (Rossman, 1938; Genell, 1939).

\footnotetext{
*Reprint requests to Professor N. T. Adler.

†Present address: Department of Obstetrics and Gynecology, Eastern Virginia Graduate Medical School, Norfolk, VA 23507 , U.S.A.
} 
Mating may facilitate sperm transport via its effect on uterine contractions. Mating-associated stimulation is known to alter the rate and strength of uterine contractions in several species (e.g. cows: VanDemark \& Moeller, 1951; VanDemark \& Hays, 1952, 1954; women: Masters \& Johnson, 1966; rabbits: Krehbiel \& Carstens, 1939; macaques: Goldfoot, Westerborg-vanLoon, Groeneveld \& Slob, 1980). Moreover, without stimulation that induces uterine contractions, the females of some species cannot achieve pregnancy (e.g. cows: VanDemark \& Hays, 1954; rabbits: Hartman, 1957).

In the rat, uterine contractions may be important for normal transuterine sperm transport. Transuterine sperm transport and uterine contractions were both reduced when the amount of intrauterine fluid was low, whether naturally or experimentally produced (Toner \& Adler, 1985).

The purpose of the present study was to analyse the relationship between mating and uterine activity. The first stage was to observe the contractile response of the rat uterus to natural, unencumbered mating. The second stage was to identify the relevant stimulus dimensions of the mating situation which were critical for the observed response.

\section{Materials and Methods}

\section{Subjects}

Twenty Sprague-Dawley female rats from Charles River Breeding Labs, aged 85-145 days, were selected from the colony. All showed regular oestrous cycles, as determined by daily vaginal smears. After the surgery to implant electrodes and balloons, females were housed singly, and had continuous access to tap water and Purina rat chow.

Males were sexually experienced, aged 110-300 days, and housed in groups of 3 or 4 . A minimum of 3 days between matings was enforced for the males.

\section{Electrode and balloon implantation}

Three pairs of electrodes, evenly spaced along the uterus, a ground electrode, and an intrauterine balloon were implanted in each female. Electrodes were Teflon-coated stainless-steel wire (diam. 0.003 in. $(76 \mu \mathrm{m})$; Medwire, Mt Vernon, NY). A $1-2 \mathrm{~mm}$ length of Teflon was scraped off the wire about $3 \mathrm{~cm}$ from one end, and the wire was bent sharply in this region. This bend was used to centre the bared area of wire in the myometrium. Wires were crimped and soldered into Amphenol minisockets (No. 220-SO2), which were placed in a $2 \mathrm{~cm}$ length of strip connector (No. 221-1660). Wires were collected into a length of Silastic tubing ( $0.64 \mathrm{~mm}$ i.d., 1.19 mm o.d.; Dow Corning Corp., Midland, MI).

The intrauterine pressure was assessed by a balloon-tipped catheter placed in the same uterine horn (Csapo, 1966; Neuman, Jordan, Ronx \& Knoke, 1972). Balloons were hand-made of latex, $0.15 \mathrm{~cm}$ o.d. and $1.50 \mathrm{~cm}$ long, and were connected to polyethylene catheters (PE60; i.d. $0.76 \mathrm{~mm}$, o.d. $1.22 \mathrm{~mm}$ ). The polyethylene tubing was joined to a curved 18 -gauge steel catheter at the animal's head. A small cap covered the exposed metal tube when not being used for recording. Water filled the balloon and catheter at all times.

At vaginal pro-oestrus, animals were anaesthetized with $0.3 \mathrm{ml}$ Chloropent $(42.5 \mathrm{mg}$ chloral hydrate, $21.2 \mathrm{mg}$ magnesium sulphate, and $8.86 \mathrm{mg}$ pentobarbitone sodium per $\mathrm{ml}$; Fort Dodge Labs, Fort Dodge, IA) per $100 \mathrm{~g}$ bodyweight i.p., which provided effective anaesthesia for 60-90 min. The skull was prepared for the headpiece by removing all membranes and treating the bone with fluoride. Four holes were carefully drilled through the cranium; a small screw was inserted in each hole. After leading the headpiece and catheter subcutaneously from the abdominal to scalp incision, dental cement (Jet Acrylic, Lang Dental, Chicago, IL) fixed the catheter and strip connector permanently in place on the skull. The balloon-tipped catheter was placed in the uterus through a small transverse incision, midway between the mesometrial and antimesometrial aspects, and just caudal to the uterotubal junction. The balloon was fixed in place by close stitches of 
absorbable 6-0 sutures (Vicryl). (Absorbable suture may produce less chronic irritation than silk sutures (Chaudhuri, 1977).)

Electrodes were placed in pairs along the uterus: the rostral pair immediately below the catheter incision, the caudal pair immediately above the bifurcation of the horns, and the middle pair midway between the outer pairs. Intrapair spacing was $2 \mathrm{~mm}$. Electrodes were placed with the help of a 30 -gauge trochar through the linea uteri, on the antimesenteric side of the horn. The linea is an antimesometrial thickening of the myometrium thought to represent a specialized conduction tissue, with distinct EMG characteristics (Melton \& Saldivar, 1967). Electrodes were secured by wrapping the free end of the wire twice around the fixed end, and clipping the remainder short. The ground electrode was placed in the rectus abdominus muscle $3 \mathrm{~cm}$ rostral to the pubic ramus (Talo \& Karki, 1976; Ishikawa \& Fuchs, 1978). Excess wire was placed in the belly; muscle and skin were closed. Postoperatively, the animals were given pentazocine (Talwin; Winthrop Labs, NY), $2 \mathrm{mg} / \mathrm{kg}$ i.m., every $8 \mathrm{~h}$ for the first 3 days for analgesia.

Beginning the day after surgery, uterine activity was recorded by a Grass model 7 polygraph. Pressure was relayed through a Statham pressure transducer (model P23Dc). The EMG and pressure leads were flexible, giving the female unlimited mobility within a $51 \times 62 \times 62 \mathrm{~cm}$ electricallyshielded box.

For EMG recording, a wide-band A.C. pre-amplifier (model 7P5a) was used, setting the halfamplitude high-frequency filter to $15 \mathrm{~Hz}$, the half-amplitude low-frequency filter to $10 \mathrm{~Hz}$, and the sensitivity in the range of $30-100 \mu \mathrm{V} / \mathrm{cm}$. This setting filtered out the fluctuating baseline characteristic of smooth muscle (Marshall, 1967, 1980), but passed action potentials signalling muscle contractions. For recording pressure, a low-level D.C. pre-amplifier (model 7P1a) was used, setting the half-amplitude high-frequency filter to $0.5 \mathrm{~Hz}$, and the sensitivity in the range of 0.05 $0.20 \mathrm{mV} / \mathrm{cm}$. This setting recorded only persistent pressure changes; transient changes were not passed.

\section{Treatments}

Three treatments were given: mating, artificial vaginocervical stimulation, and vigorous mounting by males prevented from intromitting. Nine females were gonadally intact and 11 females were ovariectomized and treated with intramuscular injections of hormones in $0.1 \mathrm{ml}$ oil: $0.10 \mathrm{mg}$ oestradiol cypionate (Hanover Drug Products, Hanover, NJ) 76 and $28 \mathrm{~h}$ before mating, and $0.50 \mathrm{mg}$ progesterone (Sigma Chemical Co., St Louis, MO) $6 \mathrm{~h}$ before mating.

Mating. Twelve females were mated: 9 were ovariectomized and 3 were intact. After at least 30 min of baseline recording, a male was placed in the arena with the female and allowed to mate. Mating was terminated after 1 ( 7 females), 2 ( 2 females) or 6 ( 1 female) ejaculatory series. Recording continued for $1 \mathrm{~h}$ when possible.

Artificial vaginocervical stimulation. To identify the relevant stimulus dimensions which produce the changes in uterine contractility, vaginocervical stimuli were separated from other stimuli which attend mating (olfactory, visual, auditory, and non-vaginal tactile stimuli). Thirteen females ( 8 ovariectomized, 5 intact) received experimenter-delivered vaginocervical stimulation in the absence of a male rat on 25 occasions. After $30 \mathrm{~min}$ of baseline recording, the plunger of a $1-\mathrm{ml}$ syringe was repeatedly pressed against the cervix (Komisaruk \& Wallman, 1977). One 'probe' was delivered each min for 5-10 min. Recording was continued for $1 \mathrm{~h}$.

Non-intromittive stimulation. Each of 20 females was also exposed to vigorous mounting by males that were prevented from intromitting. This was achieved by placing a girdle around the abdomen of males, covering the genital region. Each female, after $30 \mathrm{~min}$ of adaptation, was exposed to a girdled male for $10 \mathrm{~min}$. Recording continued for $1 \mathrm{~h}$ after the male was removed.

\section{Statistics}

Data were evaluated using analysis of variance (ANOVA) and the Tukey post-hoc test. 
Contraction rates were determined for up to 14 intervals in each female: (1) before mating (for 20-40 $\mathrm{min}$ ), (2) during active mating, (3) immediately after ejaculation ( $5 \mathrm{~min}$ ), and (4-14) thereafter (divided into successive 20-min blocks). Because recording could not always continue for $1 \mathrm{~h}$ after mating, analyses were based on the first 4 intervals only.

Log survivorship analysis (Fagen \& Young, 1978), using intervals as its data, was used to evaluate intercontraction intervals. Instead of representing each interval as an element in a bar of the histogram, each interval is assigned to a point in a two-dimensional space. The $x$-axis of this space is the interval length, as in a histogram; however, the $y$-axis, instead of being the frequency of a particular interval, is the percentage of all other intervals that are longer than the one being considered. This percentage is plotted on a log scale. For example, for 4 intervals of 1, 3, 6, and $7 \mathrm{~min}$, the point representing the 1 -min interval would be placed above the 1 -min mark at $100 \%$, since all the other intervals are longer. The second point, centred over the 3-min mark, would be placed at $67 \%$, since 2 of the other 3 points are longer. The 6 -min interval would be above 6 -min at $33 \%$, and the 7 -min interval would be marked at $0 \%$ (no intervals are longer).

This procedure has two virtues. One is that it permits a visual assessment of whether the intervals are occurring randomly in time. If they are, then the data will line up neatly along the diagonal defined by intersecting the first and last datum points. The other is that it allows simultaneous comparison of two distributions. In the present work the distributions of pre- and post-mating intercontraction intervals for each of the 12 females that were mated are presented.

\section{Results}

\section{Effect of mating}

Mating had a dramatic influence on the ongoing pattern of uterine contractions. Figure 1 shows the response of one female to mating. Before mating, there were occasional, irregularly spaced contractions; mating provoked an obvious increase in contraction rate. Then the uterus was quiet for the first $5 \mathrm{~min}$ after the ejaculation but, thereafter there was a dramatic increase in contraction rate which lasted about $1 \mathrm{~h}$.

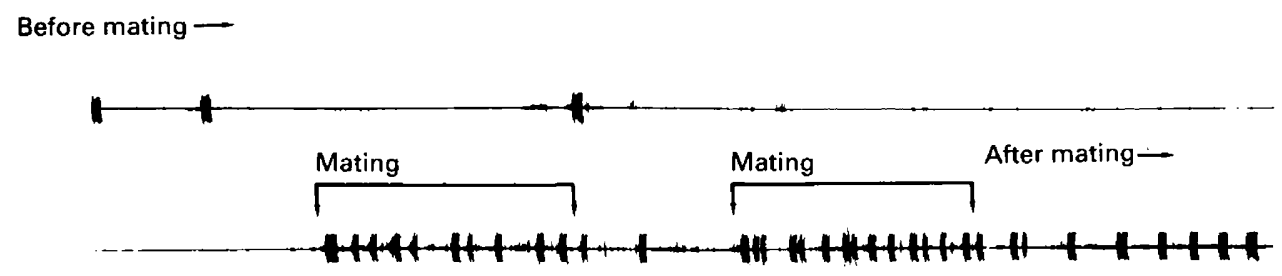

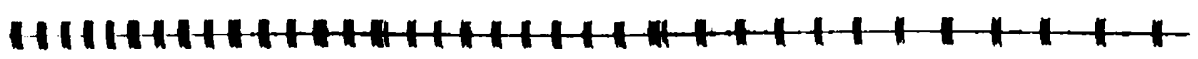

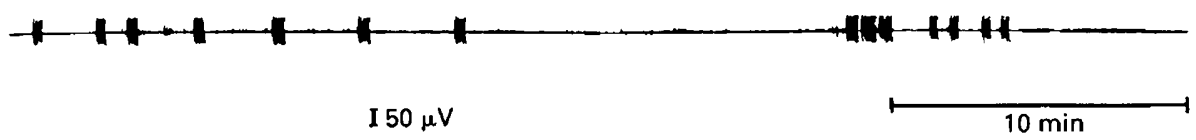

Fig. 1. Uterine response to mating in one female rat before, during and after mating. This ovariectomized, hormone-supplemented female mated through two ejaculatory series (represented by long black bars) $6 \mathrm{~h}$ after progesterone. 


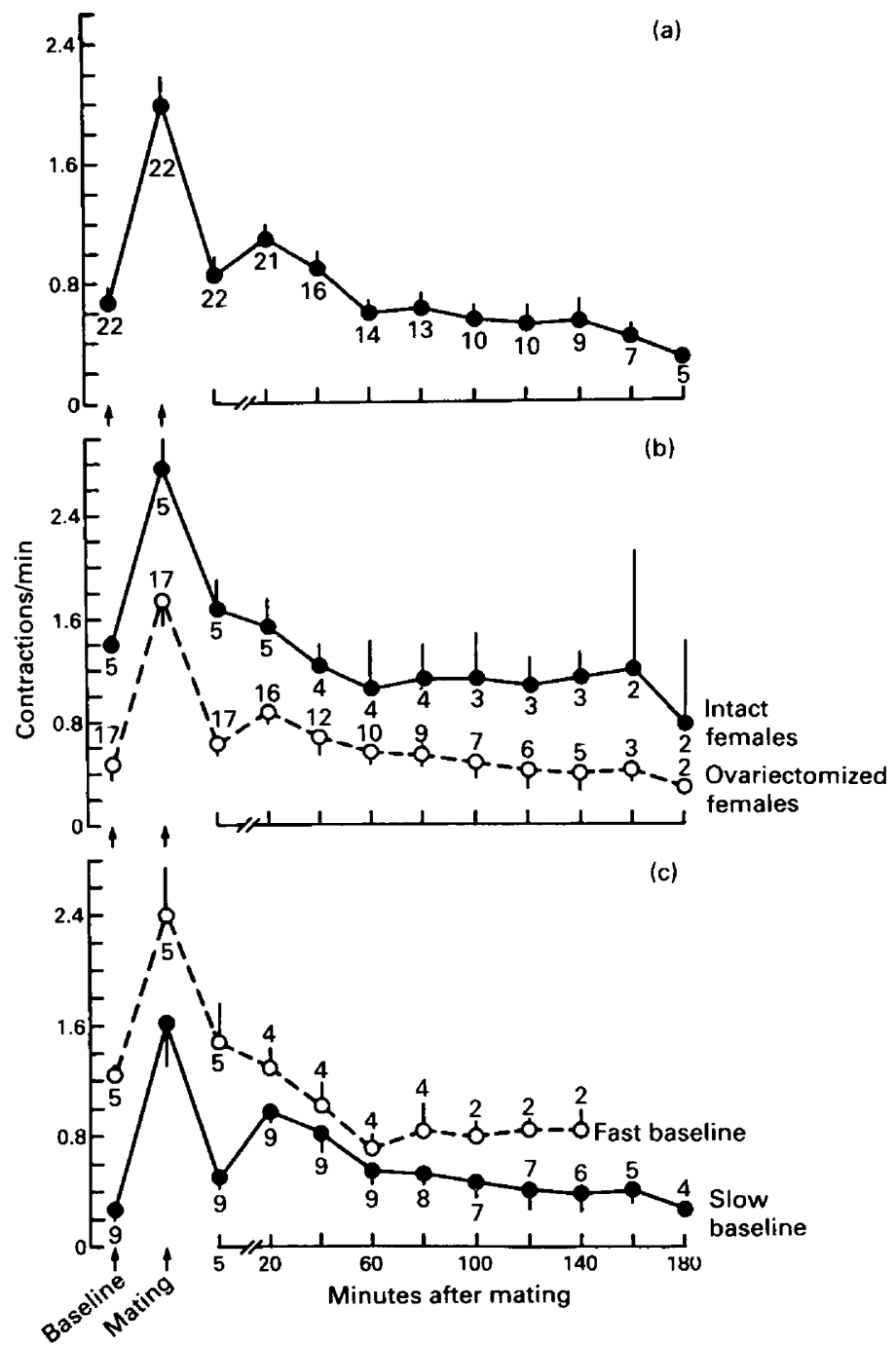

Fig. 2. The uterine response of rats to mating. Mean \pm s.e.m. values for (a) all 21 females; (b) gonadally-intact and ovariectomized females; and (c) females with a slow ( $<0.5$ contractions/ $\mathrm{min}$ ) or fast baseline value before mating. Mating was one ejaculatory series (first intromission through first ejaculation). The time after mating was divided into the first 5 -min block and then successive 20-min blocks. Bars represent the s.e.m.; the $n$ is given with each point.

Figure 2(a) shows the overall response of 21 matings of 12 females. Significant differences among the contraction rates before mating, during mating, immediately after mating (first $5 \mathrm{~min}$ ), and in the next 20 min were observed $(F(3,39)=18.94 ; P<0.0001)$.

The uterus was changed by mating from a relatively quiet organ into one that had frequent contractions during the active mating period (Tukey $P<0 \cdot 01$ ). This immediate effect occurred on all but one occasion.

After ejaculation, the rate of uterine contractions abruptly fell to near baseline levels for about 5 min on $20 / 21$ occasions (see Fig. 2a; Tukey $P<0.01$ ). 
A secondary, delayed effect followed this short post-ejaculatory period. After the post-ejaculatory return to baseline contraction rate, there was a subsequent change in contractile rate: on $15 / 21$ occasions this change was an increase in contraction rate, lasting about $40 \mathrm{~min}$. On 4 occasions the contraction rate decreased even further after this initial postejaculatory change (see below) and on 2 occasions there was no change.

Mating induced a regularization of uterine contractions. Before mating, contractions (if they occurred at all) were grouped into short isolated clusters, but after mating the long pauses between clusters were eliminated. The shorter intervals between contractions were occasionally made even shorter by mating, but long intervals were eliminated.

Figure 3 shows a log-survivor plot for each female. For $11 / 12$ females mating eliminated long intercontraction intervals. For 1 female long intervals persisted after mating; this female subsequently went into constant oestrus. In 6 females mating also made the short intervals shorter; no shortening occurred in the other 6 females.

The endocrine status of the female may have influenced the pattern of uterine contractility. Gonadally intact females had higher overall contraction rates than did ovariectomized, hormonetreated females $(F(3,36)=22.88 ; P=0.0002)$. As shown in Fig. 2(b), intact females had about one more contraction each min during the pre-mating period. Both groups responded to mating with increased contractions. After ejaculation the contraction rate returned toward the pre-mating level

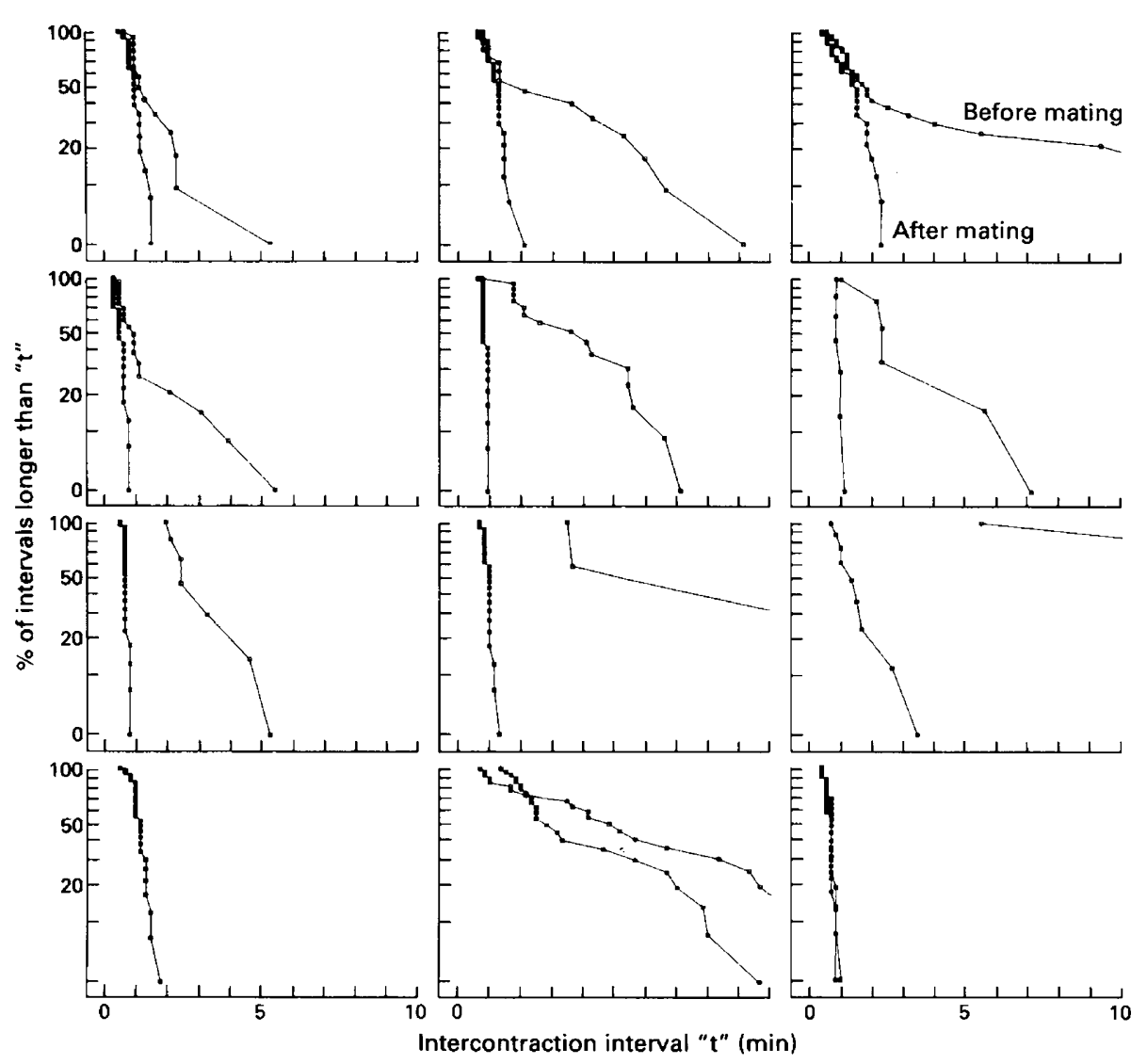

Fig. 3. Log-survivorship plots of intercontraction intervals before and after mating for each of the 12 females that were mated. 
for the first $5 \mathrm{~min}$ in both groups. Thereafter, there was some convergence of the groups toward a common contractile rate, i.e. intact females showed a further slowing towards baseline levels, while ovariectomized females showed increased contractile rate to above baseline levels.

The difference in contractile response to mating between intact and ovariectomized females may not be specific to hormone treatment but rather may reflect different responses as a function of baseline differences. All but one intact female had a fast rate of baseline contractions; all but one ovariectomized female had infrequent baseline contractions. To understand the influence of the pre-mating (baseline) contractile rate on the response to mating, females were divided into two groups on the basis of their baseline contraction rate (irrespective of hormonal status). Those with fewer than $0 \cdot 5$ contractions per min were analysed separately from those with more.

Figure 2(c) confirms that the contraction rate in the immediate postejaculatory period reflected the baseline rate. Females with infrequent baseline contractions had few contractions in the first 5 min after ejaculation, while those with a high contraction rate before mating returned to this high rate after mating. Thus in the immediate postejaculatory interval there was no evidence that mating had altered uterine contractility from its pre-mating rate. After the initial $5 \mathrm{~min}$ of the postejaculatory interval there was a 'delayed' effect of mating. Females with infrequent baseline contractions showed an augmentation of rate for the next $40 \mathrm{~min}(t=4 \cdot 38, P=0.02)$, the rate slowly drifting back to the baseline rate over the next $2 \mathrm{~h}$. Those females with frequent baseline contractions, however, showed a depression of contraction rate after mating which lasted at least $1 \mathrm{~h}$. Thereafter the rate began a slow rebound toward the faster baseline rate. During this period of convergence of contraction rate, there was no significant difference in contraction rate between two groups.

\section{Effect of artificial vaginocervical stimulation}

Stimulation of the vagina artificially partly mimicked the effect of intromissions on uterine contractions $(F(3,114)=28 \cdot 28, P<0.0001)$. Of the 25 trials of vaginal probing, 19 showed the increased contraction rate during the probing period that was typical of mating (Tukey $P<0.01$ ). The expected fall in contraction rate in the first $5 \mathrm{~min}$ after the probing had stopped was shown on 19/24 occasions (Tukey $P<0.01$ ) and a subsequent increase in contractile activity was seen on $20 / 24$ occasions $(72 \%$ of the baselines were slow $(<0.05 / \mathrm{min})$ ). While the form of this reaction was the same as observed in natural mating, the amplitude of the changes was much less than that of mating (interaction $F(1,114)=12 \cdot 35, P<0 \cdot 01$ ).

Two examples are given in Fig. 4. One female had both an immediate and a delayed response to vaginocervical stimulation (Fig. $4 \mathrm{a}$ ). The other female had no contractions before probing and only two during probing, but $5 \mathrm{~min}$ after mating began to have very regular contractions which lasted $20 \mathrm{~min}$ (Fig. 4b).

Since probing did not require that the female rat be proceptive (Beach, 1976), it was possible to assess whether the stage of the oestrous cycle had an influence on the responsiveness of the uterus to vaginocervical stimulation. Trials with experimenter probing were categorized for oestrous and nonoestrous rats. Oestrous rats included gonadally-intact females showing a nucleated vaginal smear and ovariectomized females given progesterone that day. Non-oestrous rats were the remainder. The responsiveness of the uterus was the same for the two groups. Oestrous rats had a slightly higher (non-significant) baseline contraction rate which carried through all observation periods.

\section{Effect of non-vaginal mating stimulation}

Girdled males mounted the females vigorously and repeatedly. Nonetheless, uterine contraction rate did not increase either during the period of active mounting or during the hour after the male was removed $(F(3,39)=1 \cdot 56 ; \mathrm{NS})$. 

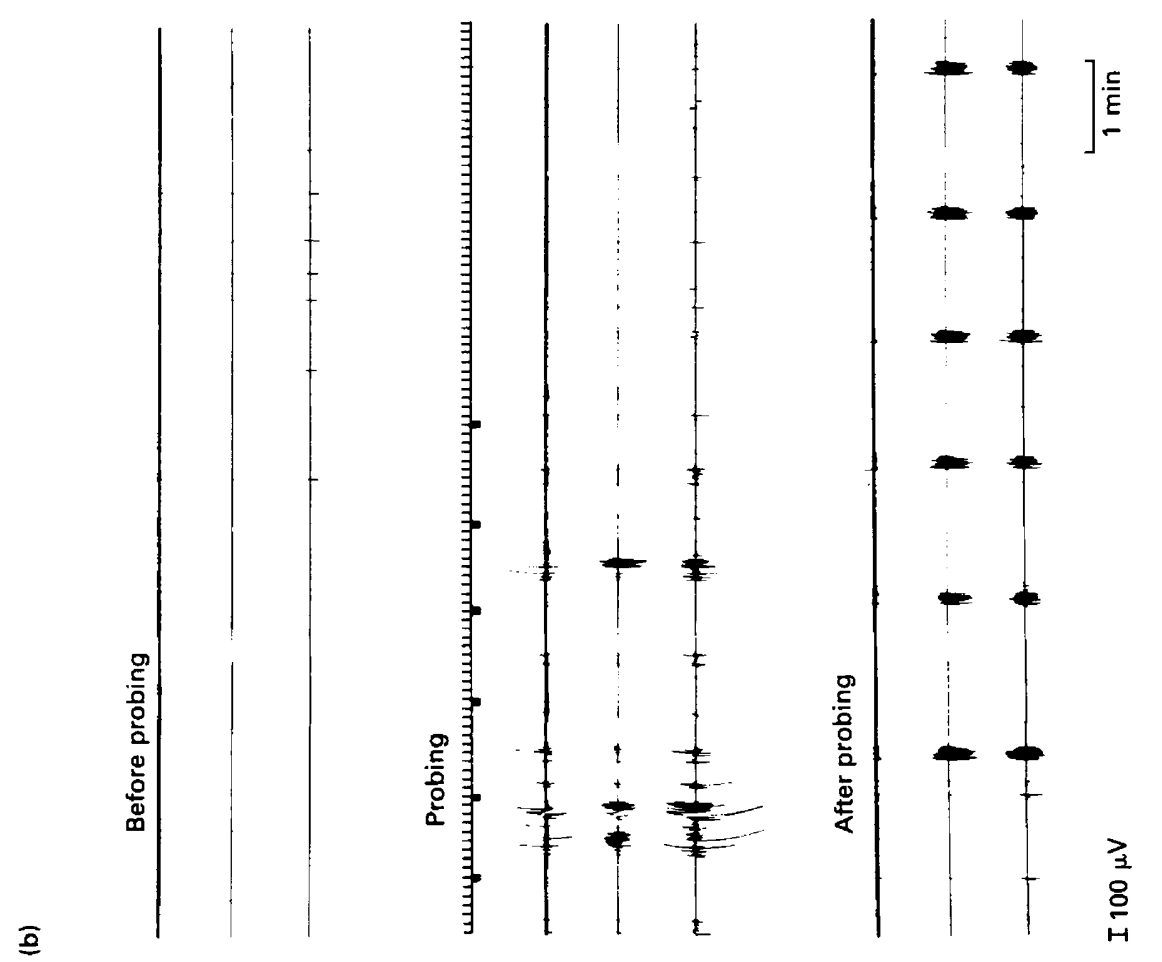

毂䔏

है

중

خิ

을

政

远

.

ธ.

응

娄安

흘

के

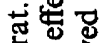

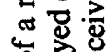

主施密要

을

踣

茎 胥

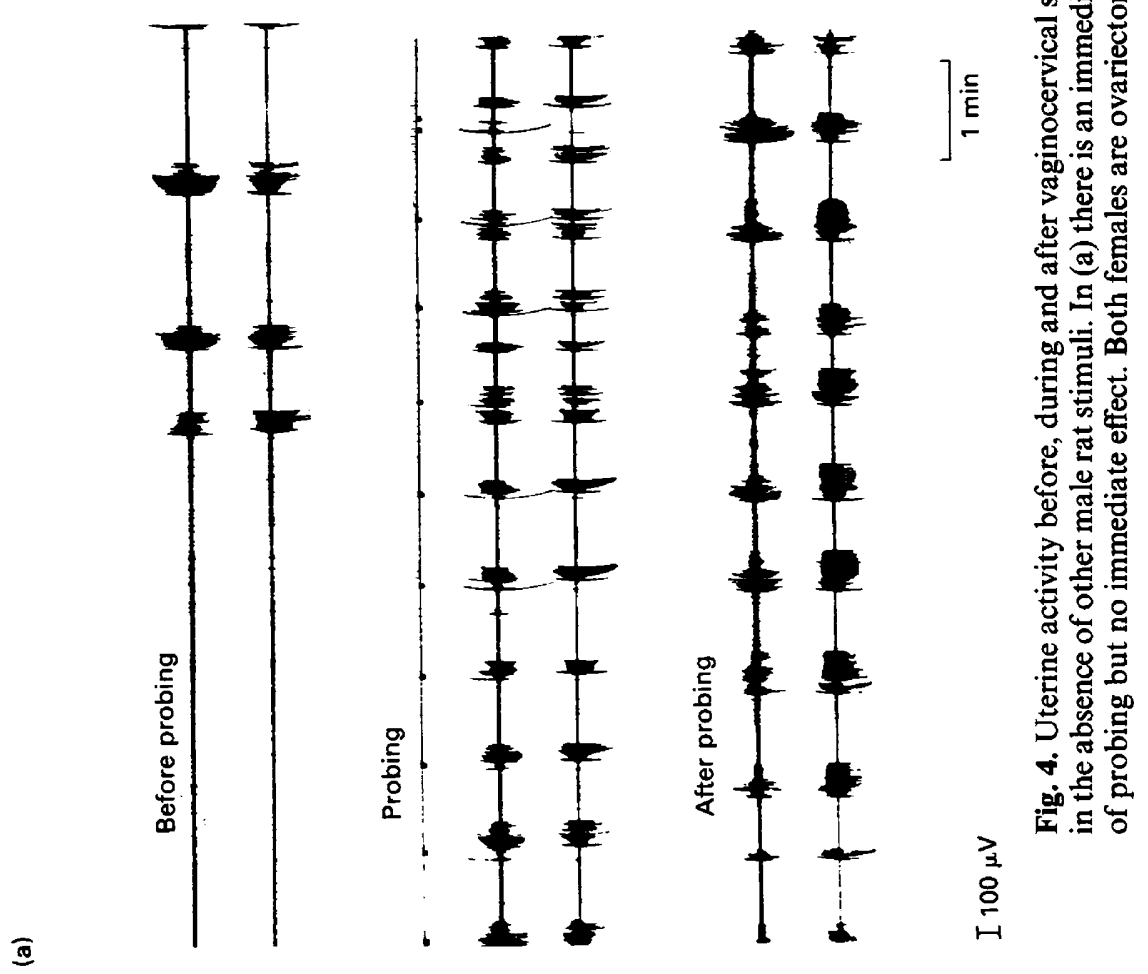




\section{Discussion}

Mating had immediate and delayed effects on contractile activity of the uterus. During the ejaculatory series, uterine contractile activity tripled. This was the 'immediate' effect. After ejaculation, the contraction rate returned to its pre-mating rate, whether it had been fast or slow. This return to baseline lasted about $5 \mathrm{~min}$. The 'delayed' effect then ensued. In contrast to the activity during and immediately after mating, activity during this delayed effect was dependent on the baseline rate. There was a convergence of contractile rate during this period, which lasted on average at least $1 \mathrm{~h}$.

These two effects of mating on uterine activity had different qualities. The immediate effect was to augment uterine contraction rate, regardless of the pre-existing rate. In contrast, the delayed effect regulated contraction rate into a narrow range.

Between the immediate and delayed effects is the post-ejaculatory interval, the time when sperm transport through the uterus is occurring (Matthews \& Adler, 1977). During this period, there was no discernible effect on contraction rate; the uterus contracted as it had before mating. It may be that the transcervical sperm transport does not significantly depend on uterine contractions. The intraluminal fluid status of the uterus (which strongly correlates with uterine contraction rate) does not correlate with the extent of transcervical sperm transport (Toner \& Adler, 1985).

However, mating did influence contraction rate beginning $5 \mathrm{~min}$ after ejaculation. At this point, many spermatozoa are already in the uterus; the bulk of transcervical sperm transport has occurred (Matthews \& Adler, 1977). These sperm encounter a uterus which contracts regularly about once each min, regardless of whether it had contracted more or less frequently before. Uterine contractions (as modified by fluid level) have been shown to affect transuterine sperm transport (Toner \& Adler, 1985). Thus, the convergence of uterine contraction rate is occurring at the time when other evidence suggests that contractions play a role in sperm transport.

Vaginocervical stimulation was an important factor in producing these changes in uterine activity rates, both 'acutely' and 'chronically'. Experimenter-delivered vaginal probing mimicked the influence of mating on uterine contraction rate. Moreover, all other stimulation provided by mating (with the exception of vaginocervical stimulation) was inadequate to provoke these responses. This gives vaginocervical stimulation 'special status' among the various stimuli of mating with regard to the uterine contractile response.

Vaginocervical stimulation has been shown to be critical for other aspects of reproduction in rats. This stimulation is critical for sperm transport (Adler, 1969), for the progestational response (Wilson, Adler \& LeBoeuf, 1965), and for ejaculatory immobility (Toner et al., 1986). While the pelvic nerve is essential if vaginocervical stimulation is to trigger the progestational response, it is not critical for other factors. Females with bilaterally transected pelvic nerves still transport spermatozoa into their uteri (personal observation; $N=4$ ), and vaginocervical stimulation will still provoke uterine contractions, both immediately and in a delayed fashion (personal observation; $\mathrm{N}=3$ ).

Experimenter-delivered vaginocervical stimulation was not as effective as natural intromissions in producing a contractile response in the uterus. Many things might account for this. The penis of the rat is barbed and therefore may provide much more intense stimulation of the area (Phoenix, Copenhaver \& Brenner, 1976; Baumgardner \& Dewsbury, 1980). The rapid, repetitive thrusting which occurs during an intromission (Bermant, 1961; Diamond, 1970) is impossible to duplicate with a human hand. The other stimuli which normally attend mating (the male's smell, sounds, appearance, etc.) are absent and may be important in an additive or synergistic way in allowing for the full response. The female cannot perform the typical behaviour which elicits mating (McClintock \& Adler, 1979); performing these behaviours may facilitate the response. Other factors may also be operating.

The baseline of contraction rates of gonadally-intact and ovariectomized, hormone-treated females were different. Intact females had more active uteri. Endocrinologically, this could be due to 
the high doses of oestrogen and progesterone given to ovariectomized females. Oestrogen inhibits spontaneous uterine contractility (Fuchs, 1974, 1976; Downing, Porter \& Redstone, 1981). Further, progesterone may augment this effect by inhibiting propagation of contractile activity (Daniel, Garfield, Kannan, Zelcer \& Sims, 1978).

However, results from the probing study suggest that the hormonal condition of the female may have a small influence on uterine responsiveness to vaginocervical stimulation. In this experiment the uterus responded to vaginocervical stimulation in a nearly identical way when females were in oestrus as when they were not in oestrus.

The uterus responds to mating by altering its contractile rate in every mammalian species yet studied. In some mammals this response is manifest by a train of short-lived contractions (e.g. rabbits: Fuchs, 1972; women: Masters \& Johnson, 1966; Fox, Wolff \& Baker, 1970). The rat also shows this pattern. In other mammals the uterus responds by increasing uterine tone (and intraluminal pressure) for a prolonged period in the form of one long contraction. Cows (VanDemark \& Hays, 1952), sheep (van derWeyden, 1983), dogs (Evans, 1933) and some primates (Goldfoot et al., 1980 ) show this pattern. In every case yet reported, the uterus responds to mating. In many cases it has been demonstrated that these contractions are linked to sperm transport and to fertility (e.g. cows: VanDemark \& Hays, 1954).

This work was supported by a Medical Scientist Training Program grant (5-T32-GM-07170) to J.P.T. and by National Institutes of Health grant (HD04522) and National Science Foundation grant (BNS-81-20816) to N.T.A.

\section{References}

Adler, N.T. (1969) Effects of the male's copulatory behavior on successful pregnancy of the female rat. $J$. comp. Physiol. Psychol. 62, 613-622.

Amerbach, R. (1930) Sterilitat und Frigiditat. Munchen. Med. Wchnscher. 77, 225-227.

Baumgardner, D.J. \& Dewsbury, D.A. (1980) Pseudopregnancy in female rats: effects of hormonal manipulations of the male. Physiol. Behav. 24, 693697.

Beach, F.A. (1976) Sexual attractivity, proceptivity, and receptivity in female mammals. Horm. Behav. 7, $105-138$.

Bermant, G. (1961) Rat sexual behavior: photographic analysis of the intromission response. Psychon. Sci., 2, 65-66.

Chaudhuri, G. (1977) The role of prostaglandins on the increase in motility of the rat uterine horn containing a silk suture. Int. J. Fert. 22, 4447.

Csapo, A. (1966) The theoretic, diagnostic, and prognostic value of uterine pressure. Bibl. gynaec. Fasc. 42, 93-124.

Daniel, E.E., Garfield, R., Kannan, M.S., Zelcer, E. \& Sims, S. (1978) The nature of control over coupling between smooth muscle cells and layers; its contribution to the synchrony of smooth muscle contraction. Jap. J. Smooth Muscle Res. 14, suppl. 37-38.

Diamond, M. (1970) Intromission pattern and species vaginal code in relation to induction of pseudopregnancy. Science, N.Y. 169, 995-997.

Downing, S.J., Porter, D.G. \& Redstone, C.D. (1981) Myometrial activity in rats during the oestrous cycle and pseudopregnancy: interaction of oestradiol and progesterone. J. Physiol., Lond. 317, 425-433.
Egli, G.E. \& Newton, M. (1961) The transport of carbon particles in the human female reproductive tract. Fert. Steril. 12, 151-155.

Evans, E.I. (1933) The transport of spermatozoa in the dog. Am. J. Physiol. 105, 287-293.

Fagen, R.M. \& Young, D.Y. (1978) Temporal patterns of behaviors: durations, intervals, latencies, and sequences. In Quantitative Ethology, pp. 82-87. Ed. P. W. Colgan. Wiley, New York.

Fox, C. \& Fox, B. (1967) Uterine suction during orgasm. Br. med.J. $1,300$.

Fox, C.A., Wolf, H.S. \& Baker, J.A. (1970) Measurement of intra-vaginal and intra-uterine pressures during human coitus by radio-telemetry. J. Reprod. Fert. 22, 243-251.

Fuchs, A.-R. (1972) Uterine activity during and after mating in the rabbit. Fert. Steril. 23, 915-923.

Fuchs, A.-R. (1974) Myometrial response to prostaglandin enhanced by progesterone. Am. J. Obstet. Gynec. 118, 1093-1098.

Fuchs, A.-R. (1976) Influence of estrogen and progesterone on uterine motility reassessed. Gynecol. Invest. 7, 99, Abstr.

Genell, S. (1939) Experimental investigations on the muscular functions of the vagina and uterus in the rat with special reference to the problem of the transport of spermatozoa. Acta obstet. gynaec. scand. 19, $113-175$.

Goldfoot, D.A., Westerborg-vanLoon, H., Groeneveld, W. \& Slob, A.K. (1980) Behavioral and physiological evidence of sexual climax in the female stump-tailed macaque (Macaque arctoides). Science, N.Y. 208, 1477-1479. 
Hafez, E.S.E. (1973) Transport of spermatozoa in the female reproductive tract. Am. J. Obstet. Gynec. 115, $703-717$.

Hartman, C.G. (1957) How do sperms get into the uterus? Fert. Steril. 8, 403-427.

Hartman, C.G. \& Ball, J. (1931) On the almost instantaneous transport of spermatozoa through the cervix and uterus in the rat. Proc. Soc. exp. Biol. Med. 28, $312-314$.

Harvey, C. (1960) The speed of human spermatozoa and the effect on it of various dilutents with some preliminary observations on clinical material. J. Reprod. Fert. 1, 84.95.

Hawk, H.W. (1983) Sperm survival and transport in the female reproductive tract. $J$. Dairy Sci. 66, 2645-2660.

Ishikawa, M. \& Fuchs, A.-R. (1978) Electrical and mechanical activity of rat uterus in vivo during the estrous cycle. Am. J. Obstet. Gynec. 132, 611-619.

Kelly, J.V. (1962) Myometrial participation in human sperm transport: a dilemma. Fert. Steril. 13, 84-92.

Komisaruk, B. \& Wallman, J. (1977) Antinociceptive effects of vaginal stimulation in rats: Neurophysiological and behavioural studies. Brain Res. 137, 85-107.

Krehbiel, R.H. \& Carstens, H.P. (1939) Roentgen studies on the mechanism involved in sperm transport in the female rabbit. Am. J. Physiol. 125, 571-577.

Marshall, J.M. (1967) Comparative aspects of the pharmacology of smooth muscle. Fedn Proc. Fedn Am. Socs. exp. Biol. 26, 1104-1110.

Marshal, J.M. (1980) Vertebrate smooth muscle. In Medical Physiology, pp. 120-148. Ed. V. B. Mountcastle. Mosby, St Louis.

Masters, W.H. \& Johnson, W.E. (1966) Human Sexual Response. Little, Brown \& Co., Boston.

Matthews, M. \& Adler, N.T. (1977) Facilitative and inhibitory influences of reproductive behavior on sperm transport in rats. J. comp. Physiol. Psychol. 91, $727-741$.

Matthews, M. \& Adler, N.T. (1978) Systematic interrelationship of mating, vaginal plug position, and sperm transport in the rat. Physiol. Behav. 20, 303-309.

Matthews, M. \& Adler, N.T. (1979) Relative efficiency of sperm transport and number of sperm ejaculated in the female rat. Biol. Reprod. 20, 540-544.

McClintock, M.K. \& Adler, N.T. (1979) The role of the female during copulation in wild and domestic rats. Behaviour 67, 67-96

Melton, C.E. \& Saldivar, J.T. (1967) The linea uteri, a conduction pathway in the rat myometrium. Life Sciences, 6, 297-304.
Moghissi, K.S. (1969) Sperm migration in the human female genital tract. J. Reprod. Med. 3, 73-85.

Neuman, M.R., Jordan, J.A., Ronx, J.F. \& Knoke, J.D. (1972) Validity of intrauterine pressure measurements using transcervical intra-amniotic catheters and intraamniotic miniature pressure transducer during labor. Gynecol. Invest. 3, 165-175.

Overstreet, J.W.\& Tom, R.A. (1982) Experimental studies of rapid sperm transport in rabbits. J. Reprod. Fert. 66, 601-606.

Phoenix, C.H., Copenhaver, K.H. \& Brenner, R.M. (1976) Scanning electron microscopy of the penile papillae in intact and castrated rats. Horm. Behav. 7, 217-227.

Rossman, J. (1938) Uterine contractions and the transport of sperm in the rat. Anat. Rec. 69, 133-134.

Settlage, D.S.F., Motoshima, M. \& Tredway, D. (1973) Sperm transport from the external cervical os to the fallopian tubes in women: a time and quantitation study. Fert. Steril. 24, 655-661.

Talo, A. \& Karki, A.E. (1976) Electrical activity of the rat myometrium in vivo during the estrous cycle. Acta physiol. scand. 97, 495-500.

Toner, J.P. \& Adler, N.T. (1985) The role of uterine luminal fluid in uterine contractions, sperm transport and fertility of rats. J. Reprod. Fert. 74, 295-302.

Toner, J.P., Attas, A.I. \& Adler, N.T. (1986) Behavioural mediators of transcervical sperm transport. Physiol. Behav. (in press).

van derWeyden, G.C. (1983) Myometrial activity in the non-pregnant Texel ewe. Doctoral dissertation, University of Amsterdam.

VanDemark, N.L. \& Hays, R.L. (1952) Uterine motility responses to mating. Am. J. Physiol. 170, 518-521.

VanDemark, N.L. \& Hays, R.L. (1954) Rapid sperm transport in the cow. Fert. Steril. 5, 131-137.

VanDemark, N.L. \& Moeller, A.N. (1951) Speed of spermatozoa transport in reproductive tract of the estrous cow. Am. J. Physiol. 165, 674-679.

Viring, S., Einarsson, S., Jones, B. \& Larsson, K. (1980) Transuterine transport of small- and medium-sized molecules deposited in the uterus in gilts. $J$. Reprod. Fert. 59, 459-462.

Wilson, J.R., Adler, N. \& LeBoeuf, B. (1965) The effects of intromission frequency on successful pregnancy in the female rat. Proc. natn. Acad. Sci. U.S.A. 53, $1392-1395$. 